\title{
Nasopharyngeal Cancer pMX TNM Finding v6
}

National Cancer Institute

\section{Source}

National Cancer Institute. Nasopharyngeal Cancer pMX TNM Finding v6. NCI Thesaurus. Code C64485.

Nasopharyngeal cancer in which distant metastasis cannot be assessed. (from AJCC 6th Ed.) 